\title{
¿Cuál es el legado de la Universidad Jesuita? Percepciones de los egresados sobre la formación humanista
}

\author{
What is the Legacy of Jesuit University? Alumni's \\ Percceptions about Humanistic Education
}

\section{RESUMEN}

Se presentan los resultados de la primera fase de una investigación que se llevó a cabo por medio de entrevistas semiestructuradas a 53 egresados de las universidades del Sistema Universitario Jesuita de los planteles de Ciudad de México, Puebla, León, Torreón y Tijuana, para recabar su opinión sobre la formación que recibieron desde el punto de vista humanista y social, específicamente en las materias de formación humanista, con el objetivo de explorar si, a pesar de las diferencias de planteles, carreras y generaciones, era posible detectar percepciones constantes que permitieran, más adelante, elaborar un cuestionario de opciones cerradas para ser aplicado a una muestra mucho mayor de sujetos. A partir del análisis, categorización e interpretación de las respuestas, destaca la clara conciencia de los egresados de haber recibido una formación de calidad en términos de visión interdisciplinar, desarrollo personal, pensamiento crítico, sentido de emprendimiento y el compromiso social, todos estos elementos constituyentes del sentido de la formación humanista, con lo cual es posible afirmar que el mensaje del humanismo de inspiración cristiana ha sido capaz de permear diferentes planteles, carreras y generaciones. Se destaca también la centralidad e importancia de la figura del docente como factor clave de la formación de calidad y se recomienda poner especial importancia en la formación docente para lograr los objetivos formativos que los egresados identifican como la esencia lbero.

Palabras clave: egresados, educación humanista, compromiso social, educación superior, docencia, educación en valores.

\section{Hilda Ana María Patiño Domínguez*}

\section{ABSTRACT}

This paper presents the results of the first phase of one research carried out through semi-structured interviews which were carried out with 53 alumni of Jesuit colleges of Mexico City, Puebla, León, Torreón and Tijuana, in order to get their opinion about their college education from the humanistic and social point of view, specifically in the humanistic core courses, with the aim of exploring whether, despite the differences in schools, careers, and generations, it was possible to detect constant perceptions so one can design later a closed options questionnaire to be applied to a much larger sample of subjects. The results, which were obtained from the analysis, categorization, and interpretation of the answers, highlight the clear awareness of the graduates of having received a quality education regarding interdisciplinary vision, personal development, critical thinking, entrepreneurship, and social commitment. All these elements constitute the sense of the humanistic formation, so it is possible to affirm that the message of the Christian-inspired humanism has been able to permeate despite the differences of schools, careers, and generations. The centrality and importance of the figure of the teacher as a critical factor in quality education is also highlighted, and it is recommended to put particular emphasis on teacher training to achieve the aims of education that alumni identify as the essence of Ibero.

Key words: college alumni, humanistic education, higher education, teaching, social responsibility

”Universidad Iberoamericana, Ciudad de México, México; hilda.patino@ibero.mx 


\section{INTRODUCCIÓN}

La Ibero me hizo una persona que no se conforma, que siempre busca ir más allá de lo que se presente, solucionar los problemas que se suscitan, comprometerme con mi realidad y querer transformarla.

Testimonio de un exalumno

La calidad educativa de las instituciones de educación superior se asocia, con frecuencia, al desempeño de los egresados en el mercado laboral. Cuando se alude a estudios de egresados, se piensa en obtener información para identificar la pertinencia y relevancia de los conocimientos y habilidades que desarrollaron en sus estudios de licenciatura a la luz de sus actividades laborales y cómo esos datos pueden aprovecharse para hacer mejoras curriculares.

El estudio que se describe ofrece una mirada distinta de los egresados, más allá de sus competencias laborales, pues examina la formación humanista que recibieron en la universidad, definida según los criterios de la propia institución, y si ésta favoreció en ellos un interés por las necesidades sociales, si incentivó su pensamiento crítico y si los impulsó a tener una orientación hacia el compromiso social, que son los parámetros con los que se define la formación humanista en las universidades del sistema jesuita. Es decir, el estudio se centró en evaluar, específicamente, el impacto de los cursos de formación humanista que el modelo de la Universidad Iberoamericana (Ibero) incluye en sus planes de estudio para las carreras que ofrece en sus diversos planteles.

Se trata de una investigación exploratoria de tipo cualitativo que incluyó entrevistas semiestructuradas a 53 egresados de los planteles de Ciudad de México, Puebla, León, Torreón y Tijuana. Se presentan los resultados a través de la categorización, análisis e interpretación de las respuestas de los egresados en las entrevistas; el sentido de la exploración fue encontrar aquellas concepciones constantes sobre la formación humanista integral y el compromiso social que permitieran elaborar, en la segunda fase del estudio, un cuestionario de respuestas cerradas. Este objetivo se cumplió con éxito y el instrumento se aplicó a alrededor de 1200 egresados, lo que constituyó la segunda fase de la investigación. 


\section{PROBLEMA DE INVESTIGACIÓN}

El problema de investigación está relacionado con las tensiones que se viven entre los sistemas y los individuos; entre las fuerzas sociales que perpetúan situaciones de injusticia e inequidad social en nuestro país y las intencionalidades educativas de una universidad que quiere formar profesionistas competentes en el mercado profesional y laboral, pero al mismo tiempo sensibles y comprometidos con las causas de la justicia, los derechos humanos, la dignidad de la persona y el bien común. En este sentido, la Iberoamericana entiende el humanismo como la formación integral que busca el desarrollo del pensamiento crítico y reflexivo, la sensibilidad a los problemas sociales, la conciencia de la interdependencia, y la orientación al servicio a los demás.

No es la primera ocasión que se realiza un acercamiento a los exalumnos en la Universidad; hace 25 ańos, estudios comparativos con egresados de otras instituciones concluyeron la inexistencia de diferencias significativas respecto al sentido del compromiso social entre los individuos encuestados (Muñoz Izquierdo, 1991, 1993). Sin embargo, la investigación que se presenta no tuvo la intención de comparar a los egresados de diferentes universidades, sino de hacer un análisis más profundo sobre la huella que la formación universitaria de la Ibero pudo dejar en ellos.

El interés fue indagar desde una dimensión cualitativa qué elementos del currículo (asignaturas, mediaciones docentes, experiencias académicas en general), intervinieron en la formación de los egresados y cómo esto les ha representado orientarse hacia la atención de las necesidades sociales y el compromiso con causas que mejoren la vida de sus comunidades, en algún sentido.

La pregunta de investigación se formuló de la siguiente manera: ¿cómo valoran los egresados la formación humanista integral y el sentido del compromiso social que construyeron en la universidad, y cómo se traduce esta formación y este compromiso en sus vidas, tanto a nivel personal como profesional? A la luz de esta pregunta, se planteó como objetivo general caracterizar la valoración de los egresados acerca de la formación humanista y social, en función de la influencia que, en su percepción, ha tenido en su vida personal, su sensibilidad y compromiso con las causas sociales. 


\section{REFERENTES TEÓRICOS}

\section{Formación humanista como formación en valores: una relación polémica}

Rastrear los orígenes de la educación humanista nos remonta hasta los griegos, concretamente, cuando los sofistas pusieron al hombre en el centro de la reflexión filosófica y de su tarea educativa. Protágoras de Abdera decía que "el hombre es la medida de todas las cosas", y su enfoque fue continuado por los grandes filósofos que les sucedieron, Sócrates, Platón y Aristóteles, todos ellos interesados en la formación de los seres humanos desde una perspectiva ética y valoral para hacer de ellos ciudadanos virtuosos. El humanismo es el paradigma bajo el cual la educación se concibe como la formación integral de una persona centrada en la adquisición de virtudes, la cuales son, a su vez, la encarnación de los valores. Este enfoque prevalecerá en Occidente con ligeras variaciones que dependerán de la época y el autor que la sostenga, pero en esencia coincidirán en la necesidad de una formación integral que atienda los aspectos nos sólo intelectuales, sino afectivos, valorales y éticos.

Concebir la formación humanista como formación en valores es un tema polémico, especialmente a nivel universitario, porque se cuestiona si es posible formar en valores a los adultos jóvenes, ya que su adquisición comienza desde los inicios de la vida en el seno de la familia. Todo depende aquí de la manera en que se entienda la educación en valores. No se trata, al menos desde la perspectiva de la educación humanista jesuita, de un adoctrinamiento, sino de la posibilidad de ejercitar un pensamiento crítico y reflexivo que permita al estudiante la consciente apropiación de los valores que han sido adquiridos en etapas más tempranas de su desarrollo como persona. En este sentido, la educación en valores en la universidad se concibe como la estrategia de ofrecer a los estudiantes espacios de reflexión y autocrítica desde los cuales puedan confrontar sus propias concepciones con las de los demás y adquirir una mayor conciencia de los valores que persiguen para formarse una visión integral de su propia profesión en el mundo (cfr. Sánchez Zariñana et al., 2013). 
Actualmente, éste es un enfoque de especial interés en el ámbito educativo, justamente porque, en general, hay una conciencia del peligro que implica la deshumanización, entendida como la pérdida de los valores que nos permiten establecer relaciones armónicas y constructivas con nosotros mismos y con los demás y con la capacidad de encontrar un sentido a la vida más allá de la acumulación materialista. Deshumanizarnos significa aquí perder la capacidad de ser empáticos con el otro, perder la sensibilidad ante el dolor del prójimo, la compasión, la solidaridad y el sentido del nosotros, para quedarnos con un individualismo egoísta; es decir, significa perder aquellos valores que nos hacen mejores seres humanos.

Sin embargo, la formación humanista, entendida como la potenciación del pensamiento crítico y reflexivo que permita analizar con mayor hondura los problemas que nos aquejan como sociedad y el papel que como individuo se tiene frente a éstos, no puede garantizar que nos convirtamos en mejores seres humanos, sino que, lo que modestamente se busca es trabajar para que los estudiantes tomen conciencia de por qué algunas conductas, actitudes y valores corresponden a una mejor versión del ser humano que otras, pero ya dependerá de la libertad de cada quién elegir por un camino de humanización o de deshumanización (Sánchez Zariñana et al., 2013).

Al respecto, Martín López Calva (2009, p. 24) sostiene que

Al parecer nos encontramos claramente frente al desafío de lograr a través del diálogo y el debate de las inteligencias, la cooperación que sume voluntades y genere compromisos hacia la tarea colectiva ... donde se reviertan las dinámicas de deshumanización creciente que hoy padecemos y donde se puedan conjurar también los peligros de una destrucción de la especie humana debida a la naturaleza, por el deterioro ecológico causado por el hombre, o debida a la civilización, por la amenaza de la guerra y los conflictos sociales que pueden salirse de control.

Revertir las dinámicas deshumanizantes implica, necesariamente, una educación que, centrada en la afirmación de la dignidad humana, promueva la realización de aquellos valores que nos hacen mejores seres humanos y que se encuentran identificados 
desde la tradición de la filosofía clásica (Sócrates, Platón y Aristóteles, San Agustín de Hipona y Santo Tomás de Aquino, entre los más importantes) y los ideales de la educación en la Ilustración (Kant, especialmente), como la capacidad de reflexión crítica, la búsqueda de la verdad, el ejercicio responsable y lúcido de la propia libertad, la conciencia de la interdependencia y la solidaridad con los demás, así como la búsqueda de la justicia, por nombrar algunos de los más relevantes valores defendidos por las diversas tradiciones humanistas.

\section{Educación humanista y universidad}

La institución universitaria fue originalmente el espacio donde se enraizó y difundió la corriente humanista a través de los siglos hasta llegar al presente. Al avanzar el conocimiento de los distintos campos disciplinares ha crecido la necesidad de una cada vez mayor especialización, y ha cobrado primacía el saber técnico y científico, pues es el que nos posibilita resolver muchos problemas complejos, y que además plantea nuevos problemas haciendo avanzar el conocimiento no por una pura aspiración de saber, sino por la necesidad de hacer, resolver y fabricar. La universidad es el principal lugar, aunque no el único, en el que el saber tecnocientífico se desarrolla y, desde luego, representa una gran contribución a la humanidad. El problema es que, ante la necesidad de desarrollar este tipo de conocimiento, se ha tendido a olvidar o, al menos, a desplazar a un segundo plano, la vocación humanista universitaria de formar personas no sólo capaces, sino éticas e integralmente desarrolladas. Este desplazamiento es preocupante porque nos aquejan serios problemas, como la corrupción y deshonestidad, la violencia, la inseguridad, la destrucción ecológica, y las grandes desigualdades e injusticias sociales, entre otros muchos que se podrían mencionar, y existe una necesidad urgente de recuperar el sentido humanista que combata el individualismo egocéntrico, el consumismo, y el materialismo que a la larga provocan vacío existencial y falta de sentido de vida, problemas que han señalado muy claramente pensadores contemporáneos como Lipovetsky (2003) y Bauman (2016), entre otros muchos. 
De este modo, a la vez que existe una tendencia a privilegiar el saber tecnocientífico, se ha incrementado la conciencia colectiva acerca de la importancia de que la educación universitaria refuerce su sentido humanista para promover en los estudiantes que pasan por sus aulas, y que algún día se convertirán en los profesionistas del futuro, los valores éticos y el compromiso social que se fincan en la afirmación de la dignidad humana.

A nivel pedagógico, la educación humanista implica centrarse en la persona del alumno (Rogers, 1989, 1996), en sus sentimientos, necesidades (Raths, 1971), experiencias previas o estilos de aprendizaje (Alonso y Honey, 2007), por ejemplo, en asignar un alto valor al desarrollo de la reflexión crítica, la creatividad, la curiosidad, la preocupación por las problemáticas éticas y las implicaciones que para los seres humanos, tanto a nivel individual como social, tiene el conocimiento, buscando las relaciones entre disciplinas y la visión de conjunto y totalidad por encima del saber especializado y fragmentado (López Calva, 2009).

La educación humanista parte de una concepción de la persona humana como sujeto-agente, dotado de conciencia, libre y racional, por lo que sus acciones son intencionales, y considera que la misma educación es un proceso de intencionalidad y de concienticidad que implica la comprensión, afirmación y transformación del mundo y del propio sujeto. Así, López Calva (1996, p. II) señala que el proceso de enseñanza-aprendizaje es, fundamentalmente, un proceso de "encuentro humano" en el que tiene lugar el diálogo atento, inteligente y razonable, así como la libre valoración sobre los diversos aspectos de la realidad que se estudia con el propósito de ampliar el "horizonte de comprensiones, significados y valores que intervienen en él” y, concomitantemente, lograr una mayor autoapropiación del sujeto.

\section{Educación humanista desde la perspectiva jesuita}

La Universidad Iberoamericana, confiada a la Compañía de Jesús, se declara como una institución que promueve el humanismo integral de inspiración cristiana. Este discurso, plasmado en sus documentos básicos, ha sido fruto de la interacción e integración de diversas posturas doctrinales que a lo largo del tiempo se 
han amalgamado y cobrado cuerpo en el crisol de los particulares contextos sociohistóricos. Hay que recordar que la Compañía de Jesús, fundada el 15 de agosto de 1534, nace en un ambiente marcadamente humanista por el fenómeno del Renacimiento, cuyas ideas y tendencias se enfrentan al mundo medieval. En medio de estos dos mundos, Ignacio de Loyola, que se había formado en la Universidad de París, acoge el espíritu humanista y el amor por los clásicos, y los conecta con la defensa de la fe católica. Una unión que podría parecer imposible, se hace realidad en la educación promovida por la Compañía de Jesús:

La pedagogía ignaciana incorporó muchos elementos de la formación humanista del Renacimiento de su tiempo ... Pero a todos estos elementos renacentistas y renovadores supo agregarles la incondicional ortodoxia cristiano-tradicional, de fidelidad a la autoridad doctrinal de la Iglesia. De esta manera, Ignacio de Loyola eligió el camino de la síntesis conciliadora de extremos antonómicos. Y por ello representa para la historia del pensamiento pedagógico la armonización del teísmo medieval con el humanismo renacentista, dentro de una fórmula nueva de pedagogía humanista cristiana (Labrador Herraiz C., 1999, p.27).

Los primeros documentos que sientan las bases de esta peculiar combinación de lo humanista con lo católico doctrinal son, principalmente, las parte IV de las Constituciones de la Compañía de Jesús (1554); la Ratio Studiorum, publicada por primera vez en 1599, y los mismos Ejercicios Espirituales (1548), escritos por San Ignacio de Loyola, en los que se ofrece una interesante metodología del discernimiento a través de una experiencia de profunda introspección para tomar decisiones de manera libre y consciente.

En la época contemporánea sobresalen dos textos: Las características de la Educación de la Compañia de Jesús (1986), que plantea el desarrollo integral de la persona, la educación para la libertad y el compromiso con las causas sociales, al mismo tiempo que la búsqueda de la excelencia, llamada magis, entre otras ideas importantes. El segundo texto se refiere a los cómos específicos dentro del aula: se trata de la llamada Pedagogía Ignaciana. Un planteamiento práctico (1996), en el que se propone un método de aprendizaje cuyos componentes son el contexto, la experien- 
cia, la reflexión, la acción y la evaluación, y que establece el papel del profesor como un acompañante, un mediador y un facilitador de los procesos de aprendizaje. Estas dos obras son documentos generales que tienen la intención de inspirar y guiar todas las obras educativas de la Compañía de Jesús.

En cuanto al nivel universitario, en México, la Universidad Iberoamericana, fundada en la Ciudad de México en 1943, plantea su concepción educativa en sus documentos básicos, el Ideario de 1968 y la Filosofía Educativa de 1985. Entre estas dos fechas, la Reforma Académica de 1974 inaugura la autonomía de la Ibero frente a la UNAM con un modelo educativo basado en la departamentalización, la interdisciplinariedad y el currículo flexible. En ella se define el humanismo como una "actitud" caracterizada por:

El pensamiento ordenado y crítico, la clara expresión oral y escrita y de toda índole; el planteamiento y la solución del cuestionamiento básico del hombre en el mundo (su origen, destino y naturaleza); la conciencia histórica, la experiencia estética; la cooperación social responsable y la congruencia entre pensamiento y conducta" (Reforma Académica, citado por Sánchez, Alfaro, Chávez, Navarro y Patiño, 2013, p.15).

En el Ideario se sostiene que uno de los fines esenciales de la Universidad Iberoamericana es "la formación integral y humana de cuantos frecuentan sus aulas", "y la Filosofía Educativa define la educación humanista como "el desarrollo integral de los dinamismos fundamentales del hombre: creatividad, criticidad, libertad, solidaridad, integración afectiva y conciencia de la naturaleza de su actuar" (Bazdresch, J., 1993, p.7).

Para hacer operativa esta formación humanista integral en las universidades del Sistema Universitario Jesuita (SUJ), se establecen varias medidas. La más notable es que se destina un cierto número de materias -que varían de cuatro a seis, según el plantel y el respectivo plan de estudios-, con el objetivo de fortalecer la for-

\footnotetext{
1 "La Universidad Iberoamericana... tiene por fin esencial la conservación, transmisión y progreso de la cultura superior objetiva, mediante la formación de los profesionistas, maestros investigadores y técnicos que México necesita, la investigación científica y, según su naturaleza, la formación integral y humana de cuantos frecuentan sus aulas". Ideario I.
} 
mación humanista de los estudiantes a través de una variedad de temas que incluyen las disciplinas de las humanidades y las ciencias sociales, y que se distinguen por una metodología pedagógica activa que busca la participación, el diálogo y el cuestionamiento crítico para que los estudiantes tengan la oportunidad de revisar sus propias opciones valorales y fundamentarlas adecuadamente (Sánchez Zariñana et al., 2013).

Si la perspectiva de cambio pasa por una educación humanista, es relevante conocer si los egresados participan de esta formación y si mediante su práctica en la vida cotidiana, personal y laboral, ponen en juego los valores señalados y contribuyen a la solución de las problemáticas sociales, sin menospreciar su desempeño técnico deseable.

En este sentido, la investigación se centró en detectar si, en opinión de los egresados, las materias humanistas les aportaron elementos para una mayor sensibilidad hacia las necesidades sociales, para tener una actitud de compromiso con ellas, un interés 300 por desarrollarse integralmente ampliando sus capacidades, más allá de la competitividad.

\section{METOdOLOGÍA}

Se trata de una investigación exploratoria cuyo objetivo fue indagar si, a pesar de las diferencias de planteles, carreras y generaciones, era posible detectar percepciones constantes que permitieran, más adelante, elaborar un cuestionario de opciones cerradas para ser aplicado a una muestra mucho mayor de sujetos, en una fase posterior de la investigación, de carácter cuantitativo. La fase exploratoria que nos ocupa se realizó mediante una metodología cualitativa, aplicando entrevistas semiestructuradas a una muestra cuyo criterio de conformación fue cubrir el mayor espectro posible de diversidad en cuanto a áreas disciplinares y profesionales, planteles de procedencia y generaciones, con el objetivo de encontrar constantes comunes en opiniones sobre la formación recibida en la universidad, como ya se comentó.

A partir de este objetivo y, a través de una discusión en el equipo de investigación, se construyó un cuestionario de 21 preguntas abiertas para el guion de entrevista (ver Anexo), el cual 
está compuesto de dos partes: en la primera se establece el perfil demográfico de los entrevistados y en la segunda se aborda la opinión de los egresados sobre la formación humanista integral que recibieron durante sus ańos de estudio universitario, especialmente en las materias dedicadas a dicha formación, llamadas "Materias de Reflexión Universitaria". Las entrevistas se llevaron a cabo durante 2015 y 2016.

\section{Perfil demográfico de la muestra}

Se convocó a los egresados a participar en el estudio mediante las redes sociales (principalmente Linkedin y Facebook) y mensajes de correo electrónico. Se aplicó la técnica de muestreo de "bola de nieve", pues se tenía el interés de tener representadas a la mayor parte de las licenciaturas que se ofrecen en el SUJ. ${ }^{2} \mathrm{La}$ meta era lograr 50 entrevistas, pero se realizaron y transcribieron 53. Se incluyeron egresados de distintas generaciones y carreras provenientes de los planteles de Ciudad de México (36), Puebla (4), León (3), Torreón (5) y Tijuana (5) del SUJ, de acuerdo con la siguiente distribución (figura 1):

FIGURA 1. Procedencia de los egresados por sede

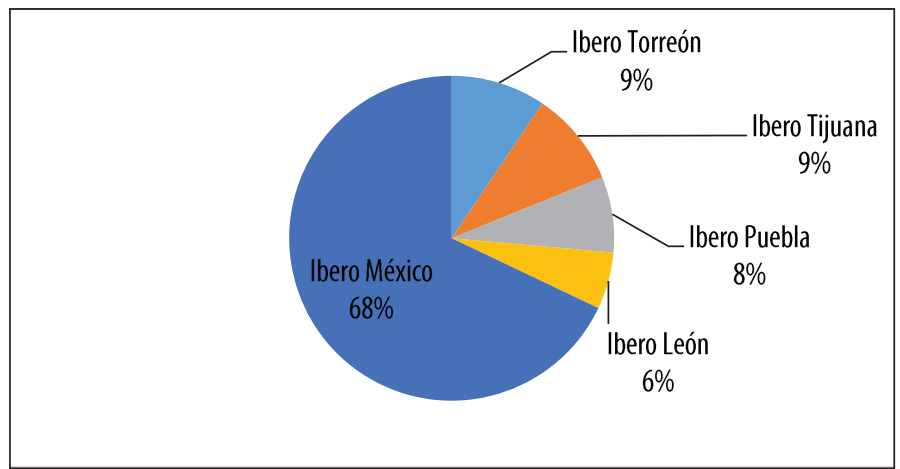

\footnotetext{
${ }^{2}$ Por las condiciones del equipo de investigación, técnicamente resultaba imposible elegir a un representante de cada licenciatura por plantel, porque hubieran sumado más de 120 entrevistas, de modo que se eligieron, la mayor parte, tratando de cubrir todas las áreas de conocimiento. 
La razón de estas proporciones se debió a la capacidad de respuesta de los egresados en las redes sociales a través de las cuales fueron contactados. La mayor parte, lógicamente, corresponden a México, que es el plantel más antiguo, con cerca de 12000 alumnos, mientras que los demás planteles tienen una población inferior a 3000 y una antigüedad mucho menor.

Como puede verse en la figura 2, la muestra estuvo compuesta por personas que egresaron entre 1978 y 2015. Las generaciones más antiguas, que abarcan las décadas de 1978 a 1997, estuvieron representadas por 14 informantes que constituyen $26 \%$ de la muestra, mientras que las generaciones más jóvenes, que abarcan las décadas de 1998 a 2015, constituyeron 62.21\%, encontrándose la moda en la generación más reciente, que abarca de 2008 a 2015 . Siete personas $(13.46 \%)$ no respondieron esta pregunta.

FIGURA 2. Año de egreso de los egresados entrevistados

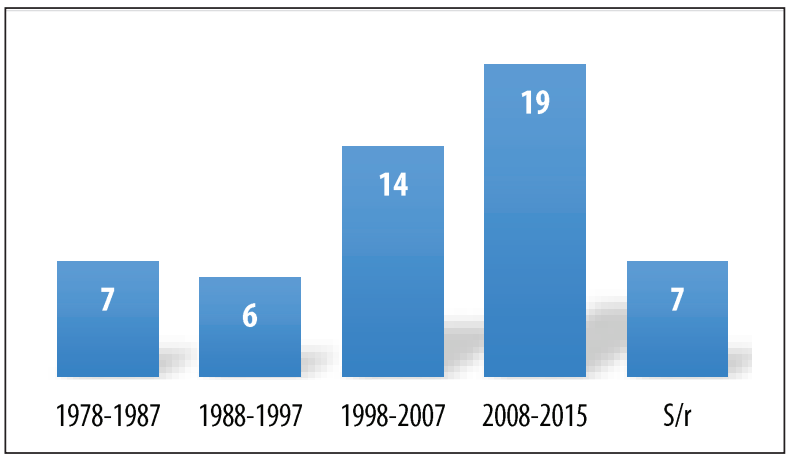

En cuanto a las carreras que abarca la muestra, prácticamente se cubre todo el espectro de las áreas disciplinares y profesionales de las que provienen las distintas licenciaturas, si bien la mayor diversidad de éstas se captó en la Ibero México, pues no fue posible lograr esto completamente, debido a las diferencias de oferta entre los planteles de la Universidad Iberoamericana en el país. La figura 3 muestra las licenciaturas de procedencia de los informantes, agrupadas por área disciplinar-profesional: ${ }^{3}$

\footnotetext{
${ }^{3}$ El área de Humanidades abarca las licenciaturas de Filosofía, Historia, Historia del Arte, Literatura y Educación. Salud incluye las licenciaturas de Nutrición y Psicología; Empresas 
¿CUÁL ES EL LEGADO DE LA UNIVERSIDAD JESUITA? PERCEPCIONES DE LOS EGRESADOS...

FIGURA 3. Licenciaturas de procedencia de los egresados por área disciplinar

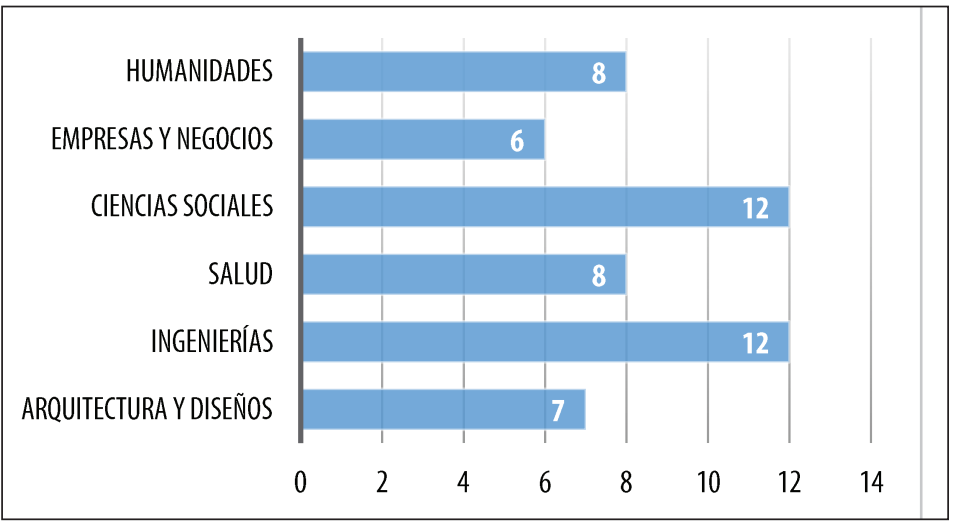

\section{Sobre la construcción de categorías y subcategorías}

Las entrevistas fueron grabadas y, en algunos casos, recopiladas a través del correo electrónico. Una vez transcritas, se elaboró un documento en el que se organizó la información tomando como eje las 21 preguntas, de modo que las respuestas de los entrevistados se agruparon por pregunta en lo que se denominó "Documento maestro". Luego, se numeraron los renglones del documento para poder extraer las citas y referirlas correctamente. Todos los informantes fueron identificados con una clave para proteger su identidad y asegurar la confidencialidad.

Una vez que se concentraron las respuestas de los informantes se procedió a revisar e interpretar cada pregunta, a fin de obtener las categorías emergentes y conformar las redes semánticas más importantes a partir del discurso de los egresados. Inicialmente, las categorías fueron extraídas de las propias preguntas de la guía, pero se atendió a su caracterización mediante subcategorías obtenidas de las propias respuestas. Así, por ejemplo, la categoría "Formación recibida en la universidad" corresponde a la pregunta:

y Negocios abarca las licenciaturas en Administración de Empresas, Contaduría, Mercadotecnia, Relaciones Industriales. Ciencias Sociales incluye Derecho, Comunicación, Administración Pública, Ciencias Políticas, Relaciones Internacionales. 
De manera general y a la distancia, ¿qué consideras haber recibido en la formación de la Ibero?

A partir de las respuestas, emergieron varias subcategorías identificadas mediante el método de codificación en vivo. Es decir, se fue revisando línea por línea para detectar lo que se consideró el núcleo básico de cada respuesta y las categorías se fueron asignando según la repetición de los temas mencionados por los entrevistados. El análisis se realizó con la ayuda de una matriz. Ésta se elaboró extrayendo las expresiones de los entrevistados, y se fueron anotando al margen los códigos. Después, se agruparon estos códigos por sus elementos comunes y así surgieron las subcategorías. El mismo proceso se realizó con las subcategorías hasta encontrar una expresión que las abarcara, según sus elementos comunes, y así se conformaron las categorías. Todo este proceso se validó colectivamente. Para realizar este trabajo, el equipo de investigación decidió dividirse por parejas y asignar la interpretación de dos o más preguntas a cada una, aunque en algunos casos, y por razones de tiempo, la interpretación fue realizada por un solo investigador.

El grupo de investigadores revisó y validó los códigos que las parejas fueron estableciendo, y se elaboraron mapas conceptuales a fin de representar gráficamente estas redes semánticas. Como toda investigación de carácter cualitativo, que utiliza el método de la codificación emergente, la interpretación es un producto subjetivo que buscó validarse de la manera más objetiva posible a través del método de discusión tanto en las binas, como en la plenaria. El aporte más valioso de la fase cualitativa exploratoria fue haber cumplido el objetivo de encontrar nociones constantes, a partir de las cuales pudo construirse un instrumento de preguntas cerradas de opción múltiple que fue utilizado para continuar hacia la fase cuantitativa de la investigación.

\section{DISCUSIÓN DE RESULTADOS}

Por razones del límite de espacio, en este artículo se discute la información de seis preguntas de la guía de entrevista que resultan de especial interés, porque muestran rasgos constantes muy 
importantes de la opinión de los egresados sobre sus experiencias formativas en la Universidad, lo que contribuye al objetivo de la investigación. De cualquier manera, el reporte completo de la misma se publicará próximamente.

\section{Sobre lo que los egresados consideran haber recibido en su formación universitaria}

Del análisis de las respuestas a la pregunta ¿qué consideras haber recibido en la formación de la Ibero?, se obtuvieron dos categorías generales: Formación de calidad y Visión de la sociedad. Se analizaron 51 testimonios, de los que 22 versaron sobre la primera categoría y 29 sobre la segunda; hay que señalar que los testimonios pueden dar cuenta de diferentes aspectos, por lo que algunas respuestas abarcan más de una categoría.

CUADRO 1. Categorías y subcategorías obtenidas del análisis de la pregunta ¿qué consideras haber recibido en la formación de la lbero?

\begin{tabular}{|l|l|}
\hline \multicolumn{1}{|c|}{ Categorías } & \multicolumn{1}{|c|}{ Subcategorías } \\
\hline \multirow{4}{*}{ 1. Formación de calidad } & Adquisición de conocimientos \\
\cline { 2 - 3 } 2. Visión de la sociedad & Calidad de la planta docente \\
\cline { 2 - 2 } & Visión emprendedora \\
\hline & Ser empático y relación con el otro \\
\cline { 2 - 2 } & Valores impartidos en las clases \\
\cline { 2 - 2 } & Formación del pensamiento crítico \\
\cline { 2 - 2 } & Compromiso con la sociedad \\
\cline { 2 - 2 } & Apertura a los cambios y a los contextos \\
\cline { 2 - 2 } & Sentido de comunidad universitaria \\
\hline
\end{tabular}

Como se observa en el cuadro 1, la primera categoría, "Formación de calidad", está tomada de la expresión de los egresados quienes ponderan, fundamentalmente, aspectos relacionados con lo que tradicionalmente se asocia a una buena educación: la adquisición de conocimientos relevantes y pertinentes y haber contado con docentes de excelencia; así, se tiene el siguiente ejemplo: 
De manera general y en términos profesionales, creo que la formación fue muy buena, sobre todo porque era una formación en gran medida teórica, que luego, dentro del campo de las ciencias sociales, pues, me permitió, al estudiar en otras instituciones, cosas que les costaban mucho trabajo a mis compañeros, como ser operativo en un concepto en investigación, pues yo las pudiera hacer. O había leído cosas que mis compañeros no tenían mucha idea de textos más recientes dentro de la historiografía y también creo que me volví más consciente de lo que pasaba en mi país, porque estuve antes en una sola escuela y mi mundito era ése (DM, 2114-2120).

Los egresados reflejan, en estas declaraciones, un reconocimiento por haber logrado aprendizajes tanto en sus respectivas áreas de conocimiento, como en otras de tipo humanista, condición que, como se señaló antes, se orienta a una formación deseable para afrontar los problemas sociales de hoy.

Sobre la planta de profesores, los relatos reconocen la buena calidad docente de la universidad y ponen de relieve la formación 306 integral y el aprendizaje mediante el ejemplo:

Excelente ya que cuenta con muy buenos docentes (DM, 1911).

Sí había una calidad académica, sí había un profesorado calificado, pero al igual que en todos los colegios Jesuitas, hay algo que no se puede medir, muy pocos lo pueden apreciar o sentir, la formación Ignaciana es por "ósmosis", no por dogma y se aprende conviviendo y en el Patria, ${ }^{4}$ cuando dejamos de ser Patria nosotros, fue cuando lo entendimos, era esa convivencia cotidiana con el Jesuita, con el profesor... (DM, 1875-1879).

Me gustó en lo académico, en lo particular, una cuestión ética muy valiosa que lo ves desde los mismos profesores que tratan de enseñarte, por un lado, con el ejemplo y por otro, también con sus propias experiencias tanto en el campo laboral como en su forma de pensar, cómo son en su campo laboral, en hacer sus cosas (DM, 2086- 2089).

Los egresados consideran que una de las principales herencias que han obtenido de la universidad es la influencia perdurable de

\footnotetext{
${ }^{4}$ El Patria fue un colegio jesuita en la Ciudad de México que cerró sus puertas en la década de los setenta.
} 
las enseñanzas de los buenos docentes, tema que se abordará más adelante. En cuanto a la visión emprendedora, se tienen respuestas como las siguientes:

La Ibero me hizo una persona que no se conforma, que siempre busca ir más allá de lo que se presente, solucionar los problemas que se suscitan, comprometerme con mi realidad y querer transformarla (DM, 1869 -1871).

Sin duda la visión de emprendimiento, o sea, antes de salir de la universidad tuve un trabajo en una empresa cosmética, de hecho, se pudiera decir que yo fui como el inaugurador del área de investigación y desarrollo de nuevos productos de esa empresa de cosméticos (DM, 2091- 2093).

Sobre todo, como que nos concientizaron sobre cómo es que, o sea, lo que tú estás aprendiendo ahí, pues sí va a ser para quizá tener tu propia empresa o trabajar en una empresa importante, pero todo lo que hagas tienes que considerar que va a tener un impacto en tu entorno y que todo el conocimiento que estás aprendiendo, pues, lo tienes que aplicar en algo bueno, o sea en algo que sirva a la comunidad en la que estás. La mente te cambia (DM, 1914-1918).

El emprendimiento es una actitud que puede contribuir a mejorar las condiciones sociales, ya que las empresas son una fuente de empleos. En nuestro país, en 2015, las micro, pequeñas y medianas empresas (MiPyMEs) generaban 73\% del empleo y $52 \%$ del Producto Interno Bruto (PIB) del país. En el mismo año, había más de 4.1 millones de microempresas que ofrecían $41.8 \%$ del empleo total; las pequeñas eran 174800 y significaban $15.3 \%$ de empleos, y las medianas sumaban 34960 lo que representaba 15.9\% de ellos (Sánchez, J., 2015, p. 26), de ahí que impulsar la actitud de emprendimiento en los estudiantes es una de las formas en las que la universidad puede contribuir a mejorar las condiciones económicas y sociales de nuestro país. Fomentar la actitud de emprendimiento requiere, a su vez, del fortalecimiento de ciertas habilidades clave como el pensamiento estratégico y creativo, la autonomía, la capacidad de tomar decisiones. En este sentido, los egresados consideran que la universidad les brindó herramientas para innovar, crear y tener iniciativa. 
También habría que señalar que la actitud emprendedora no sólo está relacionada con los negocios como actividades lucrativas, sino también con la capacidad de organizar actividades no lucrativas de beneficio social. En las entrevistas realizadas es posible constatar que $85 \%$ de los egresados dicen estar involucrados, directa o indirectamente, en actividades relacionadas con el compromiso social, las cuales realizan en espacios distintos de los de su ámbito laboral. La gama de campos de participación es muy amplia, e incluye la educación, la ciencia, la salud, la cultura, el arte, los grupos religiosos, representados en organizaciones que trabajan en favor de comunidades necesitadas. En relación con el espíritu emprendedor, se detectaron egresados que han fundado y que dirigen asociaciones de beneficio social, como puede leerse en el siguiente testimonio:

En la asociación civil que dirijo ... tenemos a 70 personas escolarizadas en habilidades sociales y laborales para mujeres adolescentes embarazadas o para mujeres adolescentes adictas recuperadas o para mujeres adolescentes rescatadas de maltrato y abuso, en un proceso de reinserción social (DM,1226; 797-802).

La segunda categoría que emergió en el análisis fue la denominada "Visión de la sociedad", que tiene que ver con la capacidad de relacionar la profesión de los egresados entrevistados con el contexto más amplio en el cual ésta se inserta, lo cual permite captar justamente su función social y la importancia de ponerla al servicio de causas más amplias.

La categoría "Visión de la sociedad" se compone de seis subcategorías. Las tres primeras fueron las más mencionadas: Ser empático y relación con el otro, valores impartidos en las clases y formación del pensamiento crítico, que comparten el aspecto central de abrir la mirada de los entonces estudiantes hacia los problemas sociales y económicos de país, y las necesidades de diversos sectores de la población, y sobre cómo es posible contribuir a cambiar ese contexto.

En cuanto a la subcategoría "Ser empático y relación con el otro", ésta se refiere al desarrollo de la capacidad de entender los pensamientos y sentimientos de los demás, y sensibilizarse ante el 
dolor y las problemáticas de los otros, tal como puede detectarse en los siguientes testimonios:

Tuve una excelente formación como psicóloga, además de que tuve un acercamiento valiosísimo a comunidades y personas con bajos recursos, así como con comunidades indígenas. Igualmente aprendí y experimenté valores humanos como la humildad, la verdad y la compasión. Tuve una experiencia muy valiosa en mi formación profesional (1859-1862).

La empatía con el otro que brinda las condiciones para que la sensibilidad hacia las necesidades sociales sea posible, y por ello es un componente fundamental de la formación humanista.

Sobre los valores impartidos en las clases, los egresados ponderan la importancia de promover en las clases valores no instrumentales que atienden al desarrollo personal desde una perspectiva ética e inclusive espiritual. Como se explicó en el apartado 2.1, no se trata de un enfoque adoctrinador que imponga una serie de valores, sino de un enfoque de discusión crítica y reflexiva que permite replantearse los propios valores y buscar aquellos que son compatibles con el desarrollo humano integral:

Una de las cosas que me llamó la atención de la filosofía de la Universidad, pues es como que están más preocupados en formar personas comprometidas con la sociedad, personas que sean capaces de insertar al mundo a un profesionista que, si bien está calificado en los aspectos de su profesión, que recuerde que hay una especie o una serie de valores que son muy importantes dentro del desarrollo del ser humano, entonces, que no podemos desasociar esos valores de una profesión (2141-2145).

Lo que yo siento que me quedó como de enseñanza a mis casi ya 40 años, es analizar las cosas un poco más profundas y no nada más en el aspecto económico o histórico, sino también en lo que a mí como espíritu me da, pero eso fue algo muy importante para mí ... siento que mi vida no está basada tanto ni en el conocimiento científico ni en la acumulación económica, sino también en mi satisfacción personal, eso es lo que me ayudó mucho haber estado en la Ibero (2105-2112). 
Otra subcategoría correspondiente a la Visión de la Sociedad agrupó los testimonios relacionados con la promoción del pensamiento crítico, que permite al sujeto replantearse los propios valores y asumirlos o reconfigurarlos de manera reflexiva, así como analizar la sociedad y hacer propuestas constructivas. Testimonios como los siguientes son ejemplo de esta aproximación:

Lo más importante (que me dejó la formación universitaria): ser participativa y hacer crítica constructiva. También ética profesional, vocación por el trabajo comunitario, la acción-reflexión y el método científico, entre otras cosas (1851-1852).

Una estructura de pensamiento crítico y una visión global de los problemas por los que pasa México y el mundo (1853-1854).

Para mí fue fundamental la formación de la Ibero para las acciones que realizo ahora, porque creo que el programa en ese tiempo, y espero que así siga siendo, se preocupaba por abrir materias que nos llevaran a pensar nuestra realidad y nuestro contexto de manera crítica, es decir, que no aceptáramos el mundo tal y como está, que pensáramos si esa realidad se ajustaba a los principios en los que creíamos e impulsaban una idea muy clara de análisis crítico de la sociedad en algunas materias, hay que decirlo, no en todas pero me pareció eso fundamental para mi formación, incluso para el resto de los compañeros de generación (2178-2184).

Esta formación valoral que se expresa en los párrafos previos, se sintetiza en la siguiente subcategoría llamada "Compromiso con la sociedad", la cual se define como la actitud y conducta de una persona que busca poner sus conocimientos y capacidades al servicio de problemáticas sociales más amplias. Este tipo de orientación se manifiesta claramente en el siguiente testimonio:

Digo un estilo de vida porque, finalmente, vas comprendiendo la fuerza interior; que sí importan mucho los conocimientos, son fundamentales, pero también esa actitud, ese carácter con el que vas a aplicar esos conocimientos y sobre todo el ver con otros ojos la sociedad, casi verlos con la mirada de Jesús. Tal vez suene muy romántico, pero recuerdo que veías a 
la sociedad con los ojos de Jesús; había situaciones de injusticia, en aquel entonces estaba de "moda" la otra campaña del EZLN; yo fui muy sensible a ese asunto y detectabas y sentías el dolor, la inconformidad de esa parte del México que a veces se nos esconde, de los indígenas (2306-2313).

Otra subcategoría se refiere a la "Apertura a cambios y contextos" y agrupa aquellas expresiones de los egresados que consideran que lo que la universidad les dejó fue la capacidad de convivir con personas de diferentes condiciones o contextos, lo que les permite incluir y no discriminar, tal como refriere el siguiente testimonio:

Lo que soy, pienso que soy capaz de relacionarme en cualquier contexto social, no discrimino, soy absolutamente allegada, me prepararon para servir a los demás, siempre tengo esta disposición de atención. Definitivamente el interés de estudiar me lo dieron en la Ibero. Mi formación en el respeto, en el escuchar, en el ser diverso, en el ser plural; todo eso lo aprendí en la Ibero (2326-2330).

Eso me dio a conocer un montón de gente, un montón de enfoques diferentes, puntos de vista diferentes. Ésa es la parte que más agradezco de haber estudiado en la Ibero (2356-2358).

Finalmente, en relación con la pregunta señalada, los egresados también mencionaron como otro aspecto valioso de su formación, el "Sentido de comunidad" que les brindó la Universidad, categoría que fue elegida para agrupar a los testimonios que privilegiaron como lo más importante que la Ibero les brindó, la capacidad de formar lazos de amistad con sus compañeros y construir relaciones comunitarias, en las que prevalece el espíritu de servicio, al estilo de los siguientes testimonios:

Sí, un sentido de comunidad, porque había un sentido de comunidad bastante importante, aunque en arquitectura se salta un poco de la dinámica tradicional de los alumnos en la universidad, yo conviví con amigos de comunicación, amigos de historia del arte, entonces ese sentido de comunidad sí me lo dio (2033-2037). 
Eso fue una experiencia que tuve, que los que conocí, que eran egresados de Ibero, de hecho, por eso los solicitábamos mucho, porque tienen una calidad de servicio y una calidez para atender a las personas, que eso creo que distingue mucho al egresado Ibero. Son personas muy serviciales y eso se valora bastante ya al momento de estar en el ámbito profesional (2265-2269).

\section{Las consideraciones de los egresados en relación con la importancia de las materias humanistas en los planes de estudio}

$\mathrm{Al}$ analizar las respuestas que se dieron a la pregunta ¿consideras importante que existan este tipo de materias [humanistas] en un plan de estudios de licenciatura?, se desprendieron cuatro categorías: "Formación interdisciplinar", "Formación humanista", "Formación laboral" y "Esencia Ibero".

CUADRO 2. Categorías y subcategorías obtenidas del análisis de la pregunta ¿consideras importante que existan este tipo de materias [humanistas]

en un plan de estudios de licenciatura?

\begin{tabular}{|l|l|}
\hline \multicolumn{1}{|c|}{ Categorías } & \multicolumn{1}{c|}{ Subcategorías } \\
\hline 1. Formación interdisciplinar & Superación de la visión disciplinar \\
& Interacción con compañeros de otras carreras \\
\hline 2. Formación Humanista & $\begin{array}{l}\text { Formación de personas } \\
\text { Sentido social } \\
\text { Pensamiento crítico y ampliación de horizonte }\end{array}$ \\
\hline 3. Formación para el ámbito laboral & \\
\hline 4. Esencia lbero & \\
\hline
\end{tabular}

Respecto a la formación interdisciplinar, es una categoría usada para registrar las opiniones de los egresados que enfocan la importancia de los cursos humanistas en otorgar la capacidad de tener una visión más amplia que supera el enfoque disciplinar y permite conectar distintas áreas de conocimiento para llegar a una apreciación más rica de la realidad: 
Sí, porque te da mayor apertura conocer otros pensamientos, el que tú salgas a una realidad y ya reconozcas que hay gente que piensa diferente, que no estés enfocado sólo a lo que tú viste o a lo que a tus compañeros les tocó, sino que recabas información de otras personas y te hace crecer, te hace aprender, reconocerte, cultivarte, conociendo acerca de las demás personas. En licenciatura ya estás más encaminado y eso te enriquece (5666 -5670).

Me parece esencial para la Ibero conservar las materias de Integración (ARU), le dan riqueza al contenido del currículo, permiten un pensamiento crítico, abren una ventana a las problemáticas sociales (5514-5516).

Esta formación interdisciplinar también tiene relación con reconocer que la interacción con compañeros de otras carreras resulta enriquecedora y con que los temas de las materias de reflexión humanista fueron útiles para ir más allá de los conocimientos y experiencias de la disciplina central que aborda la propia licenciatura. Un ejemplo de ello lo da un egresado:

Sí, por dos aspectos, porque así conoces a más gente que sea de diversas carreras y tratas con diferentes caracteres y eso te ayuda para la vida laboral, porque tratas con cualquier tipo de gente. También porque desarrollas la parte humana, la parte cultural, del espíritu, del alma; me parece importante que una persona las cultive. También el aprendizaje, le dan un poco de flexibilidad a tu mente, a tu cerebro, de no estarte enfocando nada más -en mi caso, sólo en contabilidad, sólo a números- te dan otra perspectiva (5792-5797).

En cuanto a la categoría "Formación humanista", la más relevante por la cantidad de menciones que se perfilaron en este sentido, agrupa aquellos testimonios relacionados con las siguientes subcategorías: la importancia de permitir el desarrollo de las personas, de fomentar su sentido social y de promover el pensamiento crítico que posibilita la ampliación de sus horizontes.

En cuanto al "desarrollo de las personas", esta subcategoría abarca aquellos testimonios que lo que más valoran de las materias humanistas es que les permitió desarrollar su personalidad, 
y aluden, específicamente, a los valores y la construcción de la personalidad, como se constata en los siguientes ejemplos:

Recabas información de otras personas y te hace crecer, te hace aprender, reconocerte, cultivarte, conociendo acerca de las demás personas. En licenciatura ya estás más encaminado y eso te enriquece (5666 -5670).

También porque desarrollas la parte humana, la parte cultural, del espíritu, del alma; me parece importante que una persona las cultive. También el aprendizaje, le dan un poco de flexibilidad a tu mente, a tu cerebro, de no estarte enfocando nada más -en mi caso, sólo en contabilidad, sólo a números- te dan otra perspectiva (5792-5797).

En cuanto a la importancia de la formación humanista como formación social, éste es un aspecto clave del enfoque jesuita. Lograr despertar en los alumnos la sensibilidad ante los problemas sociales y la disposición a comprometerse a tratar de solucionarlos mediante el posterior ejercicio de su profesión es lo que da sentido final a la formación humanista. Los siguientes comentarios apuntan en este sentido:

Creo que el tener una formación integral humanista, hace que tu trabajo cobre un sentido social, es decir que siempre en tu trabajo buscarás un beneficio común y no sólo el tuyo (5506-5508).

Fundamental, hacen la diferencia. Eso nos hace distintos, nos hace distintos el servicio social, el pensar que podemos ayudar y que estamos para transformar a la sociedad o al menos buscar una transformación positiva en la sociedad (5799-5801).

La tercera subcategoría, "Pensamiento crítico", se utilizó para agrupar los testimonios que señalaron que la importancia de las materias humanistas fue haber fomentado en los antiguos estudiantes la capacidad de reflexión crítica, por ejemplo:

Me parece esencial para la Ibero conservar las materias de Integración (ARU), le dan riqueza al contenido de los currícula, permiten un pensamiento crítico, abren una ventana a las problemáticas sociales (5514-5516). 
Estas características atribuidas a la formación humanista son sorprendentemente coincidentes con otro estudio relacionado con la opinión de los estudiantes Aprendizajes valiosos para la formación humanista en la Universidad: la voz de los estudiantes, cuyo objetivo general fue construir el concepto de "aprendizaje valioso" a partir de los diversos significados que los alumnos otorgan al Área de Reflexión Universitaria. Se recopilaron 4625 respuestas válidas, y desde el punto de vista de la frecuencia de menciones, las tres cosas que más aprecian los estudiantes son: a) la posibilidad de ampliar sus conocimientos en áreas distintas de su campo disciplinar o profesional; b) la posibilidad de reflexionar sobre sí mismos, la vida, su sentido y la humanidad, y c) el aprecio, respeto y aprendizaje de la diversidad (Patiño, et al., 2015). Además de estas tres categorías, en esa investigación se registraron otras cinco entre las que se encuentra la formación del pensamiento crítico, así que, como puede observarse, de alguna manera se perciben como constantes en ambas investigaciones estas características para valorar la formación humanista: la visión interdisciplinar, el sentido social, la formación de las personas, $y$ el pensamiento crítico.

En otro orden de testimonios, los egresados señalaron que la importancia de estas materias fue que les dio herramientas para desenvolverse mejor en el ámbito laboral:

El haber descubierto que podemos tener un proyecto de vida basados en ver por el otro. Un universitario marcado por el modelo educativo, lo más sencillo es salir adelante él, pero hay un pedazo de conciencia que te invita a ver por el otro, desde que estás en la carrera, pero más cuando sales $(5787-5790)$.

Sí, estoy convencida, porque pocas veces tenemos oportunidad de tener ese tipo de formación y sí considero que es una responsabilidad de cualquier profesionista; la licenciatura, al final de cuentas, te va a dar una formación que va a impactar a ese profesional y para ser un agente de cambio en cualquier ámbito en que te desenvuelvas, necesitas tener esa formación (5846-5850). 
Una última subcategoría se denominó "Esencia Ibero", para agrupar expresiones de los egresados relacionadas con los elementos fundamentales que distinguen a la Universidad Iberoamericana de otras instituciones del país. Esta categoría fue muy abundante en la información: los egresados señalaron en repetidas ocasiones que la formación humanista es un sello propio de la institución; les permite ser diferentes a otros profesionales de sus propias áreas, en relación con la manera en que han sido formados en valores, ética, profesionalismo, entre otros aspectos. Señalan que el factor diferenciador de la formación, en comparación con otras universidades, es el tema social que se busca inculcar en los estudiantes, el conocimiento de la realidad y el pensamiento crítico, así como la visión de la mejora de la sociedad, esto es lo que los hace tener esa "esencia Ibero". Ejemplos de testimonios agrupados en esta subcategoría, son los siguientes:

No diría importante, diría esencial; preferiría este tipo de formación a cualquier otra y si, finalmente, un abogado, un economista, un médico, lo que sea, le falta algún tipo de formación, ya la podrá obtener en sus maestrías o en sus prácticas, pero si lo que vamos a dedicar es a una transmisión de un conocimiento técnico por el conocimiento, mejor cerrar la universidad (5695- 5698).

Sin duda, definitivamente, si quitamos las materias de reflexión, pues entonces, ¿qué nos va a distinguir de cualquier otra universidad? Ya no le pongan Universidad Iberoamericana, pónganle Tecnológico iberoamericano... Si quitamos las materias, yo creo que se pierde una buena parte de la identidad de la Ibero; entonces, yo considero que es parte de su identidad y quitarlas sería desastroso (5755- 5760).

Finalmente, las recomendaciones que los egresados hicieron para mejorar el área curricular de reflexión universitaria consistieron, básicamente, en la posibilidad de crear nuevas materias, que puedan contribuir aún más a sensibilizar sobre la necesidad de transformar la sociedad y que el menú de temáticas sea atractivo para los estudiantes. 


\section{La importancia del contenido de la materia y la actuación del profesor, a juicio de los egresados}

Otra pregunta de la entrevista exploraba la opinión de los egresados en relación con la importancia que le asignan al contenido de las materias de reflexión y a la intervención docente, como factores relevantes para su formación. Al respecto, la mayoría de los entrevistados señalaron que el manejo didáctico era fundamental, mientras que otro grupo de testimonios resaltaron que ambos elementos son complementarios, tal como se observa en el cuadro 3 .

CUADRO 3. Categorías y subcategorías obtenidas del análisis de la pregunta ¿entre el temario/contenido y el profesor de las materias ARU, cuál consideras que es más importante?

\begin{tabular}{|l|l|}
\hline \multicolumn{1}{|c|}{ Categorías } & \multicolumn{1}{|c|}{ Subcategorías } \\
\hline 1. Profesor & Didáctica de la enseñanza \\
\hline 2. Materia & Relevancia del contenido \\
\hline 3. Ambas & Complemento entre materia y didáctica del docente \\
\hline
\end{tabular}

Parte de los entrevistados mencionaron que algunos profesores específicos marcaron sus procesos de aprendizaje mediante su forma de ser, por su capacidad para atraerlos al conocimiento y al contenido que deseaban enseñar. El dinamismo, el entusiasmo de su enseñanza, la capacidad de tocar sus corazones con los contenidos que abordaban se convirtió, para varios, en el eje de la relevancia de la materia cursada, no sólo por el conocimiento nuevo, sino por quien lo enseña y cómo lo enseña. Un par de expresiones de este tipo señalan:

El profesor porque, finalmente, puede haber un programa del aprendizaje esperado del alumno, pero si el profesor no despierta este interés en los alumnos, si no logra hacer que todos se integren, que haya una dinámica sana en el grupo, pues, puede el profesor dar lecturas, clases y lo que sea pero, pues, no hay realmente un enriquecimiento, un aprovechamiento en la materia, no hay diálogo, no hay construcción; entonces, si el profe- 
sor domina todo esto y engancha a los alumnos, pues, puede cambiar el temario y a nosotros nos es irrelevante (6104-6109).

Yo creo que el quid del éxito de una materia que tiene que ver con formación humana, que tiene que ver con reflexión universitaria, que está en el papel del profesor; será su entusiasmo, su convicción y su congruencia lo que pueda llevar realmente al éxito; si alguien da esta clase porque no tiene otras opciones laborales o porque fue lo que le quedó o porque es lo poco que sabe, va a ser imposible que despierte el entusiasmo, la duda, la reflexión, la participación de los alumnos (6051-6054).

El segundo grupo, considera que el contenido que se ofrece es lo más relevante; en esta categoría los sujetos hicieron hincapié en el complemento que existe entre la materia enseñada y la metodología de enseñanza del docente. Para ellos, la temática es relevante, los contenidos fueron atractivos, pero el complemento de un contenido y un docente que supo abordar el conocimiento significativamente. de manera atractiva y amena, tiene mayor realce. Es fundamental para los sujetos que esto sea un complemento para las enseńanzas de reflexión universitaria; un testimonio en este sentido es particularmente ilustrativo:

Ambos son importantes. Un temario que esté enfocado a un verdadero crecimiento y formación humana; pero un buen temario sin un buen profesor es como un Ferrari en manos de un inexperto (5882- 5883).

Ésta es una definición precisa para comprender la relevancia y significado que tienen tanto la materia como el docente que la imparte. El contenido puede ser el mejor, la guía de aprendizaje perfectamente estructurada, con una lógica precisa y perfecta, pero en las manos de un docente que no demuestre interés y compromiso con lo que enseña, no se verán los resultados esperados.

Estas respuestas se complementan con las que se dieron a otra interrogante que exploraba si recordaban alguna materia o profesor especialmente relevante, de manera positiva o negativa; al respecto aportaron recuerdos de experiencias desafortunadas, en las que se mencionó el deficiente manejo didáctico por parte del docente. 
CUADRO 4. Categorías y subcategorías obtenidas del análisis de la pregunta ¿recuerdas alguna materia o maestro del ARU especialmente relevante, de manera positiva o negativa?

\begin{tabular}{|l|l|}
\hline \multicolumn{1}{|c|}{ Categorías } & \multicolumn{1}{|c|}{ Subcategorías } \\
\hline \multirow{3}{*}{ Recuerdo de una mala experiencia } & Mala didáctica/mal profesor \\
\cline { 2 - 2 } & Falta de exigencia académica \\
\cline { 2 - 2 } & Falta de madurez del propio alumno (actitud o disposición del alumno) \\
\hline
\end{tabular}

En relación con esto, se tienen el siguiente testimonio:

La otra fue una clase de Historia de México, me pareció una visión muy estereotipada de la conquista. Tal vez para un público más general la materia resultaba más interesante, porque se enteraban de cosas que nunca habían escuchado (4498-4503).

Otra posibilidad de una experiencia negativa consiste en la poca exigencia académica o un manejo teórico que no parece relacionarse con la realidad y que, por tanto, resulta aburrido o contribuye a la imagen de que las materias humanistas son "para rellenar" el plan de estudios. En los siguientes testimonios se muestran este tipo de comentarios:

Entonces, eso es lo malo que yo siento de casi todas las materias de reflexión que tuve, casi todas eran de relleno; insisto, pero no creo que sea cosa de los estudiantes, siento que no porque seas historiador puedes dar clases de ésas (4475-4477).

Sobre las respuestas de los egresados que evidencian haber vivido una mala experiencia al cursar las materias de reflexión, la mayor parte señalan que se trató de un mal profesor; otras refieren condiciones de diversa índole como: incompatible disponibilidad de horarios, desinformación sobre el contenido de las materias y poca disposición del propio estudiante. Ejemplos de inconformidad sobre los profesores se muestran en los siguientes testimonios: 
De manera negativa, hubo dos clases en específico que no me encantaron, de una no me acuerdo ni del nombre y de la otra era una de las obligatorias, que el profesor no me encantó, pero, pues, una mala experiencia no fue. El profesor de "Introducción al problema social" me parecía muy aburrido, como que no lograba conectarse con nosotros ni que reflexionáramos mucho sobre el mundo, aunque finalmente lo hacíamos, pero como que ya llevaba su esquemita y no había mucho diálogo (4489-4493).

Deficiencias, que lo quieren manejar de una forma muy teórica, con muchos ejemplos, pero no lo ves en la realidad. Necesitan llevar un poco más hacia la práctica; llevar a la calle lo que nos están tratando de dar para que tenga un impacto real en los jóvenes, porque no todos tienen la misma percepción (4513-4516).

En el aspecto negativo, si es que le puedo encontrar alguno, recuerdo que el profesor de "Introducción al problema del hombre", la primera vez que lo llevé, se la pasaba hable y hable, muchas cosas de filosofía que a mi nivel no entendía pero, poco a poco le fui agarrando la onda. Lo único negativo fue que reprobé "Introducción al problema social" (4389-4393).

$\mathrm{Al}$ analizar estas memorias, se destacan los factores involucrados para calificar como negativa la interacción con un docente: la deficiente habilidad didáctica, la tendencia a imponer puntos de vista o limitar la expresión de ideas opuestas a los estudiantes, la dificultad para hacer contacto con los alumnos de generaciones distantes. En contraparte, la vinculación empática con estudiantes, la habilidad para entusiasmarlos por los temas abordados, la creación de un clima de libertad de expresión en el aula y el uso de métodos activos de enseńanza son circunstancias que hacen percibir el desempeño docente como positivo.

Los testimonios que califican de negativa la experiencia de cursar materias de reflexión y señalar que son "de relleno" parecen estar sustentados en la falta de disposición o involucramiento de los estudiantes, por un lado, pero de manera más importante, por la falta de habilidades didácticas o el estilo autoritario docente, por el otro; así se tienen relatos como: 
Por ejemplo, la de psicosocial, el profesor era buena gente, pero nadie le hacía caso. De las 32 clases yo creo que hubo cinco. Si permiten eso, le quitan seriedad y se va contagiando a otras materias; las clases pierden mucho respeto (4819-4821).

Después, ya parece como campamento de verano en la clase y era un desastre porque íbamos a platicar todos, entonces vamos a platicar todos en la clase de integración, eso también, como que le faltó un poco de formalidad a algunos profesores (4414-4416).

Es interesante notar que cuatro testimonios seńalaron que la falta de madurez, compromiso y esfuerzo de los propios estudiantes también fueron motivo para desperdiciar la oportunidad formativa, como se muestra en estos comentarios:

Te lo puedo decir así, pero no le puedo echar la culpa al maestro, yo creo que también es responsabilidad mía, yo creo que también no hubo química con ese profesor ... aparte, hace 20 años yo estaba en un proceso de encontrarme a mí mismo; entonces, yo te podría decir que tenía pensamientos que haya tenido en ese momento no hayan sido los más correctos (4395-4402).

Pero como todo mundo iba a las integraciones con la esperanza de subir su promedio, porque para eso son para muchos, era de que "claro de que aquí me voy a sacar un diez, porque voy a subir mi promedio", haces lo que se te da la gana, te duermes, la gente echa flojera, no te integras, no participas... (4470-4472).

Estas declaraciones son interesantes, ya que muestran cómo la percepción y la opinión sobre las vivencias cambian con el tiempo: quienes cuando estudiantes se enfocaron en cursar materias con el propósito de obtener buenas notas sin mucho esfuerzo o sin tomar en serio los contenidos, ahora, como egresados, expresan que hubieran preferido tener mayor presión de los profesores para aprender y aprovechar la oportunidad formativa. Este análisis es especialmente útil para el diseño y operación de las materias de reflexión universitaria, que en ocasiones, para los estudiantes, pueden parecer secundarias, y tal vez para algunos 
docentes también ya que disminuyen la exigencia académica, y con ello la oportunidad de un fortalecimiento en aspectos de formación ética y de pensamiento crítico de los estudiantes. Aun con estas experiencias desafortunadas, el reto de incluir materias que no tienen una aportación técnica asociada al área de conocimiento y la condición de contar con grupos heterogéneos en los que se combinan alumnos de distintos perfiles, parece tener buenos resultados, ya que son más los testimonios positivos que los de fracaso.

\section{La apreciación que hacen los egresados sobre el valor de promover la formación humanista a nivel universitario}

La última pregunta analizada hacía referencia al valor que los egresados dan a la promoción de la formación humanista en la educación superior. De las respuestas se desprende la apreciación clara de que la elección de la Universidad Iberoamericana se funda en su prestigio académico, así como en su sello de identidad, que es la formación humanista.

CUADR0 5. ¿Consideras que vale la pena promover la formación humanista a nivel universitario?

\begin{tabular}{|l|l|}
\hline \multicolumn{1}{|c|}{ Categorías } & \multicolumn{1}{c|}{ Subcategorías } \\
\hline 1. Valor de la formación humanista & Impulso para realizar actividades basadas en el compromiso social \\
\hline 2. Promoción de la formación humanista & Difundir información sobre materias humanistas \\
\hline 3. Papel central del profesorado & \\
\hline
\end{tabular}

Los egresados conceden un papel inicial y preponderante a las materias en las que se brinda la formación humanista, que se consideran espacios de reflexión, de promoción del diálogo y del sentido crítico, como se deja ver en el siguiente relato:

Considero que sí vale la pena, me parece que la propuesta de formación humanista hace la diferencia de la Ibero con otras instituciones educativas privadas, incluso creo que podría ampliarse para formar y fomentar 
el pensamiento crítico. La conciencia social y política podría ser un eje transversal en todas las materias (6240-6243).

Una característica importante en cuanto a la impartición de las materias de reflexión es que se aprovechen estrategias que permitan su vinculación con situaciones reales, como pueden ser prácticas o talleres.

Otro elemento señalado por los entrevistados consiste en realizar una difusión eficaz sobre los temas que tratan las materias de reflexión y su importancia en relación con el modelo educativo universitario, ya sea mediante actividades internas o externas al campus, exposiciones e incluso a través del uso de la comunicación digital:

Con una campaña de comunicación estratégica que construya mensajes muy sublimes, atractivos y convincentes. Utilicen herramientas de comunicación como mensajes de texto, apps, Whatsapp, Facebook, Twitter (DM, 6808-6810).

Además de lo dicho, las respuestas brindadas a esta pregunta reiteran algunos aspectos que ya se han mencionado en las anteriores, que muestran la valía de la formación humanista de acuerdo con la experiencia de los entrevistados, ya que permite la generación del pensamiento crítico, la apertura de horizontes, el diálogo multidisciplinario, la empatía y el compromiso social. Asimismo, se reiteró la relevancia del desempeño del docente como pieza clave en este tipo de formación. Un elemento novedoso consistió en la recomendación del uso de los medios digitales para difundir información sobre las materias de reflexión.

\section{CONCLUSIONES}

Las respuestas de los egresados durante las entrevistas presentan amplias coincidencias con las que se recabaron en una investigación previa sobre el mismo aspecto de formación humanista, pero con estudiantes de la institución (Patiño et al., 2015), quienes aseguraron que las materias formativas les proporcionaron: mayor cultura general, les permitieron ampliar sus horizontes, 
fomentaron su pensamiento crítico y su sensibilidad sobre los problemas sociales. Básicamente, la opinión de egresados y estudiantes no difiere; probablemente, los primeros asignan una importancia un poco mayor a su formación humanista, junto con su logro del perfil de egreso, vistos al paso del tiempo, señalando incluso que estos aspectos marcan la diferencia con exalumnos de otras universidades.

Otra coincidencia que llama la atención consiste en el reconocimiento que se da al docente para obtener la formación esperada. Los egresados mencionaron que, en conjunto, un buen docente, que maneje un buen programa de estudios, potencializa los efectos positivos de aprendizaje del grupo. Puede considerarse hasta cierto punto normal que los alumnos reconozcan a sus buenos profesores, y que ellos se conviertan, incluso, en modelos de vida, pero este hecho todavía es más notable cuando los egresados pueden recordar el nombre de sus maestros, la materia que impartían, e incluso experiencias de clase de manera bastante vívida 324 a pesar de los ańos que han transcurrido desde su egreso, lo que indica que les dejaron una huella profunda. Como ellos mismos comentaron, los maestros que recuerdan del área de reflexión fueron capaces de conmover sus emociones, y el nuevo conocimiento se aprendió por quien lo enseñó y por cómo lo hizo.

En un estudio previo (Patiño, 2015), se indagó sobre los rasgos que distinguen las prácticas docentes efectivas de los docentes universitarios; entre los hallazgos se identificaron características de un auténtico docente, como: el dominio de la materia, la actualización constante de sus conocimientos, el interés manifiesto porque sus estudiantes aprendan, su empatía y sensibilidad al trabajar con sus grupos y detectar intereses, motivaciones e inquietudes, sus habilidades de comunicación efectiva, su trato sencillo y su imparcialidad. De las descripciones que los estudiantes dieron en ese estudio, se desprende que la docencia efectiva puede definirse como:

Una actividad de solidaridad e intercambio con el otro, que implica una relación en la cual el maestro se da a la tarea de cultivar la inteligencia propia y la del alumno, para que él pueda decidir por sí mismo y "encontrar su camino" (Patińo, 2015, p. 228). 
En este sentido, los comentarios de los egresados coinciden con los hallazgos de la investigación señalada sobre lo que hacen los docentes de excelencia, pues mencionaron, en síntesis, que específicamente en las materias de reflexión universitaria, el entusiasmo, la convicción y la congruencia del profesor son los elementos que favorecen el éxito de estas materias. Además de estas características de los docentes efectivos, los egresados reconocieron que éstas se complementan con un contenido interesante y un abordaje atractivo por parte de los profesores, por lo que las lecturas pertinentes, el análisis crítico de las mismas, la discusión grupal, los cuestionamientos controversiales, la aplicación de lo aprendido a situaciones cotidianas y profundizar sobre las motivaciones y valores que subyacen las propias acciones, son estrategias relevantes que identificaron en los docentes de ARU como aquéllas que les dejaron huella.

Los participantes de otro estudio sobre estudiantes (Patińo, et al., 2015), señalaron que la educación en valores es algo prioritario para la universidad y que tiene que hacerse retomando los valores que ya tienen los estudiantes, de modo que logren un mejor discernimiento que los impulse hacia la autonomía; los factores que destacaron son: la conciencia que debe tener el docente de que siempre educa en valores, su capacidad para promover el cuestionamiento y la reflexión, ayudar a descubrir valores constructivos y relacionar los valores con la vida cotidiana. Asimismo, los estudiantes reconocieron que parte de la formación humanista integral consiste en promover un sentido de compromiso social y de actuar en favor de los valores de solidaridad y corresponsabilidad para contribuir a mejorar situaciones concretas (Patiño, et al., 2015).

El modelo de una formación integral orientada a la valoración y decisión ética se ve hoy en día amenazada por una tendencia creciente a la especialización, que es proclive, como lo ha visto Edgar Morin (2001) a perder la visión del conjunto y la religación de las partes con el todo. Ante la magnitud de los problemas causados por los avances tecnológicos, Morin señala que existe la necesidad urgente de que la educación promueva un conocimiento capaz de abordar los problemas globales y fundamentales para inscribir los conocimientos parciales y locales en un contexto más amplio 
que incluya consideraciones y valores de carácter ético. En este mismo orden de ideas, Martín López Calva, en un extenso trabajo en tres tomos que titula Educación humanista (2009), sostiene que la actual globalización económica, que supone un cambio acelerado, nos ha llevado a una crisis mundial que se refleja en la dinámica existencial del vivir de prisa y abandonar los hábitos de la reflexión, que exige tiempo y distancia. Estamos compulsivamente impelidos a responder de manera casi inmediata a los estímulos del medio y a esperar respuestas rápidas, sin importar lo superficiales que puedan ser.

De acuerdo con este planteamiento, una educación humanista o humanizante es aquella que promueve la realización de aquellos valores que nos hacen mejores seres humanos, como la capacidad de reflexión crítica, la búsqueda de la verdad, la afirmación de la dignidad inalienable de la persona humana, el ejercicio responsable y lúcido de la propia libertad, por nombrar algunos de los más relevantes valores defendidos en las diversas tradiciones humanistas. La institución universitaria fue, originariamente, el espacio en el que esta tradición humanista se enraizó y difundió a través de los siglos hasta llegar al presente pero, al mismo tiempo, con los avances en todos los campos disciplinares, se ha convertido más bien en el "templo" del conocimiento especializado y del saber tecnocientífico. Hoy día, sin embargo, probablemente debido a los problemas sociales que nos aquejan, el vacío existencial y las grandes desigualdades e injusticias sociales, se ha incrementado la conciencia sobre la importancia de que la educación universitaria refuerce su sentido humanista para promover en los estudiantes que pasan por sus aulas, y que algún día se convertirán en los profesionistas del futuro, aquellos valores que salvaguarden la dignidad humana y las causas de la justicia.

En este orden de ideas, los egresados consideraron que las materias de formación humanista son relevantes y hay que mantenerlas en los planes de estudios, e incluso reforzarlas.

Es importante señalar que el modelo educativo de la Universidad Iberoamericana incluye un currículo flexible en el que las materias se organizan por áreas, y se gestionan mediante servicio departamental, entre las que se encuentra el área de reflexión universitaria (ARU), que responde a la intención de la educación je- 
suita de incluir contenidos de humanidades y reflexiones de tipo ético, como señala Gil Coria (1999, p. 361):

La educación de la Compañía debe insistir en la formación integral de sus alumnos mediante la exigencia de un currículum básico que incluya humanidades, filosofía, perspectivas teológicas, cuestiones sociales y otros aspectos semejantes, como parte de los programas educativos especializados. Y además ... el sistema de complementación curricular, en orden a subrayar las implicaciones humanas, éticas, sociales más profundas del programa académico.

Las materias que se imparten en el ARU tienen la intención de ampliar el horizonte intelectual y afectivo de los estudiantes, función que, si bien también tienen el resto de las asignaturas, las de esta área se diseñan específicamente para este fin, pues pretenden

ayudar a los alumnos a buscar su propia identidad y el sentido de su vida en un contexto social que parece privilegiar lo meramente sensitivo, lo no reflexivo, lo fragmentario, lo insolidario, por sobre el estudio cotidiano y esforzado, la reflexión, el conocimiento y la corresponsabilidad social (Sánchez Zariñana et al., 2013, p. 24).

Según los egresados entrevistados, vale la pena vincular estas asignaturas con proyectos de servicio a comunidades, con organizaciones de la sociedad civil, y dar a conocer los contenidos que abordan las materias del ARU mediante exposiciones, e incluso aprovechando las redes sociales para describir el contenido de las materias y sensibilizar al estudiantado.

En algunos de los testimonios destaca la emotividad que manifiestan los exalumnos cuando hablan de abrir sus horizontes, de ampliar su perspectiva más allá del campo de conocimiento de su respectiva carrera, y de sensibilizarse a la diversidad de opiniones y formas de pensar, más aún cuando estas materias constituyen alrededor de 10\% del total de asignaturas en los planes de estudio de licenciatura. Asimismo, el sentido de pertenencia que se refuerza en la convivencia con compañeros de otras disciplinas es notable. 
Finalmente, tomando en consideración que los entrevistados pertenecen a generaciones muy distantes entre sí, parece ser que los propósitos de desarrollo que buscan las materias de formación humanista se alcanzan en buena medida, por lo que se puede afirmar que la Ibero ha logrado instrumentar y mantener su propuesta formativa humanista a través de los ańos.

\section{REFERENCIAS BIBLIOGRÁFICAS}

Alonso, C. y Honey, P. (2007). Los estilos de aprendizaje: procedimientos de diagnóstico y mejora. Bilbao: Universidad de Deusto, Instituto de Ciencias de la Educación.

Bauman, Z. (2016). Modernidad Liquida. México: Fondo de Cultura Económica.

Bazdresch, J. (1993). ¿Cómo hacer operativa la formación humanista en la Universidad? CRU 14. México: Universidad Iberoamericana.

328 Gil Coria, E. (1999). La pedagogía de los jesuitas, ayer y hoy. Madrid: Universidad de Comillas.

Labrador Herraiz C. (1999) "Estudio histórico pedagógico" en Gil Coria, E. (1999). La pedagogía de los jesuitas, ayer y hoy. Madrid: Universidad de Comillas.

Lipovetsky, G. (2003). La era del vacío. Ensayos sobre el individualismo contemporáneo. Madrid, España: Anagrama.

López Calva, M. (2009). Educación humanista. Tomo I. México: Gernika.

Muñoz Izquierdo, C. (1991). El papel de la educación en la formación de las actitudes y los valores de los egresados. Revista UMBRAL XXI, 6. México: Universidad Iberoamericana.

Muñoz Izquierdo, C. (1993). Formación universitaria, ejercicio profesional y compromiso social: resultados de un seguimiento de egresados de la Universidad Iberoamericana. México: Universidad Iberoamericana.

Patiño, H. et al. (2015). Aprendizajes valiosos para la formación humanista en la universidad. La voz de los estudiantes. México: Universidad Iberoamericana. 
¿CUÁL ES EL LEGADO DE LA UNIVERSIDAD JESUITA? PERCEPCIONES DE LOS EGRESADOS...

Raths, E.L. (1971). Cómo enseñar a pensar. Teoría y aplicación. Buenos Aires: Paidós

Rogers, C. (1989). La persona como centro. Barcelona: Herder.

Rogers, C. (1996). Libertad y creatividad en la educación: el sistema "no directivo". Barcelona-México: Paidós.

Sánchez Zariñana, H., Alfaro, G., Chávez, M., Navarro, A. y Patiño, H. (2013). Programa de Reflexión Universitaria Fundamentación y Prospectiva. Colección Cuadernos de Reflexión Universitaria, 29. México: Universidad Iberoamericana.

Sánchez, J. (2015). Cuentos de Cuentas. Pymes. Revista Proteja su dinero, 180. Recuperado de https://www.condusef.gob. $\mathrm{mx} /$ Revista/index.php/historico-revista/category/17numeros-2015

\section{ANEXO. GUÍA DE ENTREVISTA}

\section{Delimitación del perfil del entrevistado:}

5. Nombre (establecer que permanecerá confidencial).

6. Sexo.

7. Licenciatura que estudió en la Ibero.

8. Generación a la que pertenece (ingreso antes de 2004 o después de 2004). Año de ingreso y año de egreso.

9. ¿Perteneces a alguna organización profesional, política, cultural, deportiva o religiosa? ¿Cuáles?

10. Participación en organizaciones, movimientos o grupos con fines de beneficio social.

11. Realización de actividades de beneficio social de manera personal/independiente y frecuencia.

\section{Opinión sobre la formación recibida}

12. ¿Por qué elegiste la Ibero para estudiar?

13. De manera general y a la distancia, ¿qué consideras haber recibido en la formación de la Ibero?

14. ¿Alguna, vez durante la licenciatura, escuchaste hablar de la formación humanista integral? 
15. ¿En qué materias fuera del área de Reflexión Universitaria consideras haber recibido una formación humanista integral? ¿De qué manera?

16. ¿Cómo ha influido en tu vida y/o en tu desempeño profesional la formación humanista? ¿Puedes darnos algún ejemplo concreto?

17. Número de materias que de ARU/Integración que recuerdas haber cursado.

18. ¿Cómo elegiste las materias? ¿Recuerdas con qué actitud o disposición ingresaste/cursaste las materias del ARU?

19. ¿Recuerdas alguna materia y/o maestro del ARU/Integración especialmente relevante, de manera positiva o negativa? ¿Qué aciertos y/o deficiencias viste?

20. Específicamente, ¿consideras que las materias del ARU/Integración tuvieron algún impacto en ti? Si tu respuesta es afirmativa, ¿cuál ha sido?

21. ¿Consideras importante que existan este tipo de materias en un plan de estudios de licenciatura? ¿Podrías ampliar tu respuesta?

22. Entre el temario/contenido y el profesor de las materias ARU, ¿qué consideras que es más importante?, ¿podrías ampliar tu respuesta?

23. ¿Consideras que vale la pena promover la formación humanista a nivel universitario? ¿Cómo lo harías?

24. Relátame alguna experiencia significativa de tu vida como estudiante en la Ibero.

25. Comentarios adicionales. 